\title{
Elimination of the Potentially Dangerous Asteroid “Apophis” Using Electric Rocket
}

\author{
Alexander Rubinraut \\ Design Office, Expeditions to Planets (EXPLANET), Munich, Germany \\ Email: rubinraut32@mail.ru
}

How to cite this paper: Rubinraut, A. (2019) Elimination of the Potentially Dangerous Asteroid "Apophis" Using Electric Rocket. Advances in Aerospace Science and Technology, 4, 17-28.

https://doi.org/10.4236/aast.2019.42002

Received: March 11, 2019

Accepted: June 9, 2019

Published: June 12, 2019

Copyright $\odot 2019$ by author(s) and Scientific Research Publishing Inc. This work is licensed under the Creative Commons Attribution International License (CC BY 4.0).

http://creativecommons.org/licenses/by/4.0/

(c) (i) Open Access

\begin{abstract}
A project of elimination of potentially dangerous asteroid Apophis which April 13, 2029 year approaches to Earth at a distance of $36,000 \mathrm{~km}$ is considered. The elimination is carried out by means of asteroid disintegration into small fragments as a result of nuclear explosion, which is produced 133 days before the moment of maximal convergence of the asteroid Apophis with Earth. In the project, a method of phased timely delivery of nuclear charge on the surface of the asteroid is proposed. In the first stage, the nuclear charge using carrier rocket "Delta" is delivered into Earth orbit. In the second stage, the charge using electric rocket is transferred from Earth orbit into the orbit of asteroid Apophis and is descended onto its surface. For implementation of the project, the design of electric rocket ER-7, which uses electric rocket engines type MARS and solar panels based on gallium arsenide is developed. Design of landing capsule, which has a chemical rocket engine and the container in which located the nuclear charge of 6 megaton is developed.
\end{abstract}

\section{Keywords}

Crazy Asteroid Apophis, Electric Rocket, Nuclear Charge, Landing Capsule, Electro Rocket Engine Type, MARS, Solar, Battery Based Gallium, Arsenide

\section{Introduction}

The article is devoted to solution of the problem of timely elimination of the threat of collision of the Earth with a "crazy" asteroid of large sizes.

The "crazy" asteroids are the solid space bodies with diameters ranging from hundreds of meters to several kilometres, which suddenly appear and move at a speed exceeding $20 \mathrm{~km} / \mathrm{s}$ out the asteroid belt to the direction of the planet Earth. To date, there are more than 10 thousand of such asteroids.

As scientific calculations show, the collision with such an asteroid can lead to 
the cataclysms, which mean the end of human civilization. Surely people must not allow that to happen.

It should be also kept in mind opinion of scientists, that the current state of science and technology is quite enough in order to provide Earth protection from the asteroid danger [1].

There are two methods of protection. The first one is to change the trajectory of the asteroid. The second method: the splitting of the asteroid into small fragments that do not reach the Earth. As shown in [1], the most effective way of asteroid destroying is nuclear explosion. In the work of Russian scientists [1], the study of crazy asteroid destroying using nuclear charge, which preliminary is delivered on its surface is made. The study is based on the principle of physical modelling of the processes, where the energy output of nuclear explosion is simulated by a pulseenergy output of laser radiation.

In physical model, an asteroid with a diameter of hundreds of meters is replaced by a mini model of few millimetres in diameter. This mini model is subjected to impact of damaging laser pulse with the energy order 500 joules within a few nanoseconds.

The studies carried out on the physical model have shown, for example, that for destruction of the asteroid with a diameter of $200 \mathrm{~m}$ the energy of explosion $6 \mathrm{MT}$ is necessary.

This is the result, in which we are interested primarily. It is known that today the greatest danger to the survival of humanity as a whole is asteroid "Apophis". According to astronomers calculations the asteroid Apophis in April 2029 year flies past Earth at a distance of only 36 thousand $\mathrm{km}$. Apophis has diameter of $325 \mathrm{~m}$ and mass of 50 million tons. Scientists have calculated that in the event of a collision, the energy released in the explosion, will be at least 500 MT. Asteroid "Apophis" was discovered at the observatory Kit-Peak relatively recently in year 2004. NASA scientists on $99.7 \%$ are sure that this sufficiently large asteroid in the year 2029 does not touch Earth. But quite probably that the day will come when the asteroid can appear, which will inevitably collide with the Earth. In this case it will be possible to save Earth from collision only through activities aimed at the implementation of a nuclear explosion, which has been modelled by scientists in [1].

But at first it is necessary to solve the problem delivery of nuclear charge on the surface of the asteroid. For that it should be developed the landing technology of a space craft on asteroid surface in automatic mode and with high degree of accuracy. Due to very small gravity in this case some specific problem arises. This became clear in 2014 year after studies conducted using spacecraft "Rosetta" [2], which was developed by scientists of the DLR.

It should be recalled that space apparatus "Rosetta" was launched towards comet 67 P7/C-G, which is in the asteroid belt, in the March 2004 year using rocket Ariane-5. November 12, 2014 year "Rosetta" reached the comet 67 P7/C-G, and was carried out the landing of landing module "Philae" on the surface of the Comet P7/C-G. 
For the implementation of the soft landing an electrrocket engine was installed at the Philae. In addition the "Philae" had a tripod with harpoons, which were supposed to provide grip of the landing module with the comet surface.

As an analysis of the landing process has shown, the landing module after touching has bounced off the surface and landed far from the calculation point. Thus it became clear that the harpoons have not worked [2].

But despite of it, the apparatus "Philae" has performed $80 \%$ of experiments that were planned by the program, and eventually the Rosetta mission was successful.

And nevertheless this space experiment has proved that the gripping device of the landing module should be further elaborated.

Developing of the reliable way of timely delivery of nuclear charge on the surface of the asteroid which is dangerous for Earth existence is the subject of the present study.

In the research process, the various ways of delivering nuclear charge, using existing launch vehicles of different design, were examined.

Calculations performed on mathematical models have shown that it is most expedient to implement the phased movement of the charge from the surface of the Earth to the surface of the asteroid "Apophis".

In the first phase the charge is put into circumterrestrial orbit. In the second phase, using electric rocket, the charge is transferred along a trajectory from Earth's orbit to orbit asteroid "Apophis" and descends on its surface. Design of the similar rocket was developed by the author of this work in 2016-2017 years for the solution of generalized task of implementation of the interorbital flights in solar system from Mercury to Mars [3].

The electric rocket [3] is set in motion by using superconducting electrorocket engine and as the source of electrical power for the operation of the engine is used solar cell based on gallium-arsenide. Description of the electric rocket design is given below.

The concept of the electric rocket flight from Earth orbit into the orbit of the asteroid Apophis.

Astronomical calculations have shown that the maximum convergence of asteroid Apophis with Earth happens on Friday April 13, 2029 year. It is quite clear that in order to determine the exact trajectory of electric rocket which we're going to send for liquidation of the asteroid, the astronomical data are required concerning the position of the asteroid in solar system during period from the second half of the year 2028 and up to the first half of the year 2029.

The analysis of the publications on this issue has showed that the problem is solved on the basis of on-board angular measurements of the system of "Sky (Nebosvod)", which were carried out by corporation "Comet" [4].

Evaluation of the accuracy determination of motion parameters of the asteroid Apophis on basis of measurements made by complex "Sky" has been performed by young scientists of Moscow Technical University (MVTU). 
The numerical results of the analysis, which we reproduce in Figure 1, were presented in [4].

Figure 1 shows the calculated trajectories of asteroid Apophis-curve 1 and planet Earth-curve 2 for the period from June year 2028 up to May year 2029. The calendar position of Earth is fixed by points 1 - 9, the position of asteroid Apophis is fixed by points 1' - 9'.

The temporal coordinates of points and the distance between them in space are shown in Table 1.

As it can be seen from Figure 1 trajectory of the asteroid Apophis is close to a circle which is shifted relative to the centre of the solar system, with a radius of 130 million $\cdot \mathrm{km}$. The maximum distance between the celestial bodies in July 2028 year is 93 million $\mathrm{km}$, and the minimum distance- 0.036 million $\mathrm{km}$ is 9 April 2029 year.

The concept of flight from Earth orbit into the orbit of the asteroid Apophis has been developed using the experience of designing of flights towards planets of the solar system [3]. The spacecraft, which performs the task of eliminating potentially hazardous asteroid is shown in Figure 2.

It consists of an electric rocket 1 and a capsule 2, which descends on the surface of the asteroid. The rocket and the capsule are interconnected using a docking unit 6.

Electric rocket "ER-7" is put into Earth orbit using the carrier rocket Delta 4. For providing movement between the orbits, four electric rocket engines type MARS (developed by the author in 2006-2016 [3] [5]) are installed on the rocket ER-7.

Energy supply for electro rocket engines 3 is provided by solar cells made of gallium-arsenide. The nuclear charge is located in the internal cavity of the

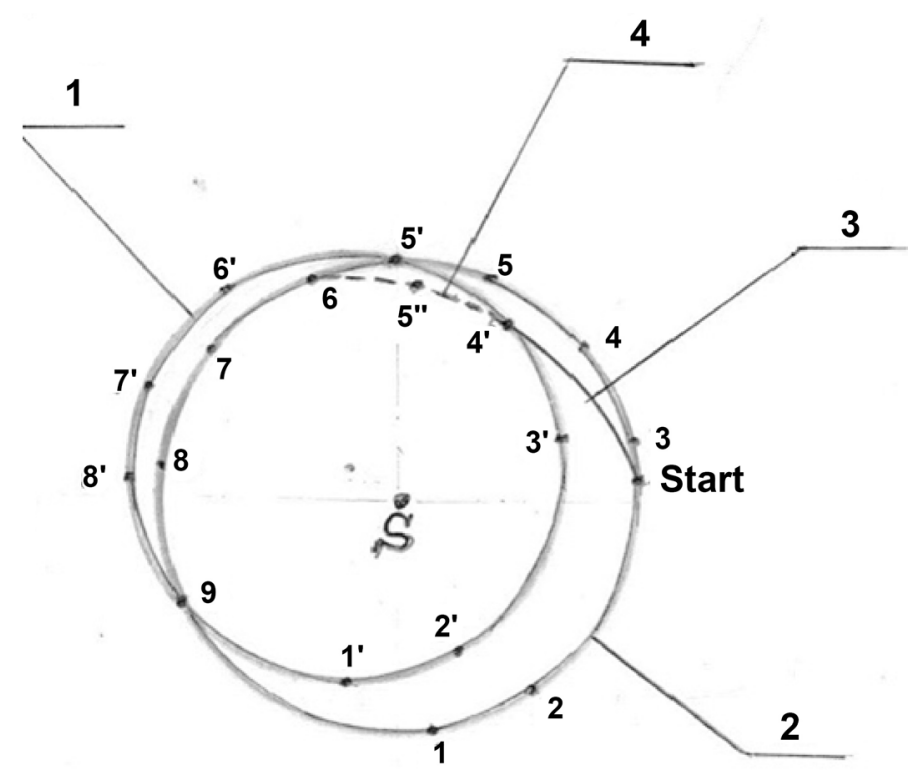

Figure 1. Evaluation of the accuracy determination of motion parameters of the asteroid. Apophis on basis of measurements made by complex "Sky". 


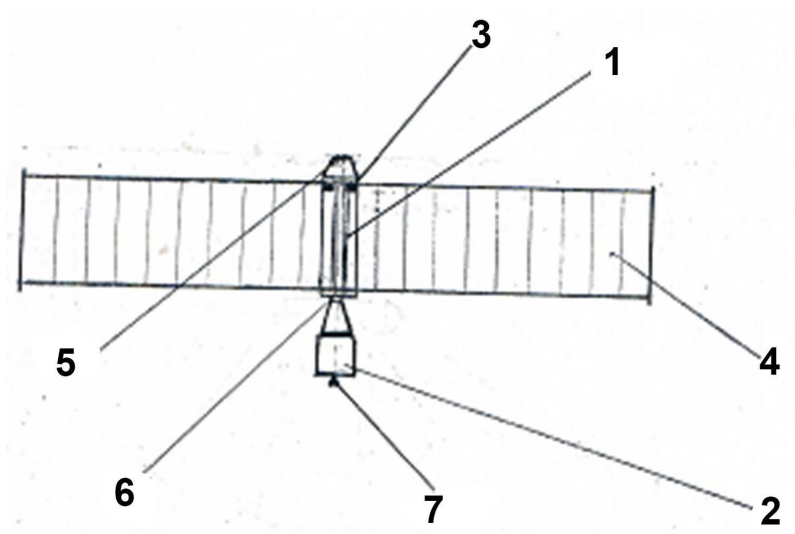

Figure 2. The spacecraft, which performs the task of eliminating potentially hazardous asteroid.

Table 1. The temporal coordinates of points and the distance between them in space.

\begin{tabular}{cccccccccc}
\hline Earth & 1 & 2 & 3 & 4 & 5 & 6 & 7 & 8 & 9 \\
\hline Apophis & $1^{\prime}$ & $2^{\prime}$ & $3^{\prime}$ & $4^{\prime}$ & $5^{\prime}$ & $6^{\prime}$ & $7^{\prime}$ & $8^{\prime}$ & $9^{\prime}$ \\
$\begin{array}{c}\text { Time } \\
\text { Distance, }\end{array}$ & 1.7 & 1.8 & 1.10 & 1.11 & 1.12 & 14.1 & 14.2 & 14.3 & 14.4 \\
million km & 93 & 68 & 44 & 60 & 64 & 50 & 33 & 16 & 0.036 \\
\hline
\end{tabular}

landing capsule. For autonomous movements along Earth orbit and orbit of asteroid Apophis the capsule 2 has chemical rocket engine 7. Landing capsule 2 is put into Earth orbit using carrier rocket Delta 4 Medium. Design description of the landing capsule is given below.

The derived initial data [4] has enabled to perform the calculation of optimal regime of flight towards the asteroid Apophis.

Let us trace (using Figure 1) the flight process, which is carried out in automatic mode. Start ofthe orbital flight is appointed on 24.09.2028. By this time the electric rocket 1 (Figure 2), which useful load is the capsule 2 with nuclear charge, must be already at starting position in Earth orbit.

But at first into the Earth orbit the locomotive 1 (Figure 2) is put and unfolding of solar panels 4 is carried out.

By means of the second launch the landing capsule 2 is put. Into the same orbit around Earth the electric engines 3 of locomotive 1 are being switched on and it starts to approach the landing capsule 2. The chemical rocket engine 7 of the capsule 2 is being switched on.

While moving along the orbit, the locomotive 1 and capsule 2 are approaching towards each other. After the approaching, docking of the locomotive 1 and the capsule 2 is carried out using docking unit 6 .

After entering on the start position, electric rocket engines are switched on and electric rocket (Figure 2) begins the flight from Earth orbit onto orbit of asteroid Apophis.

Calculation of the electric rocket flight trajectory has been carried out by using the astrodynamical program, which determines the strength of the interaction 
between the rocket and the bodies located in the planetary solar system at a given point of time. In so doing, the picture of gravitational field affecting on the rocket, as on a body of variable mass is determined. [6].

Using the method of successive approximations firstly the acceleration value and then the speed of the rocket are determined.

The calculated flight trajectories of electric rocket 3 and 4 are shown in Figure 1 , and the process of changing the speed and mass of the rocket in time is shown in Figure 3.

During the start 24.09.2028 traffic control centre generates the activating signal.

The electric rocket engines 3 are switched on and the rocket speed begins to increase. During the day the rocket reaches the second cosmic velocity and turns into a satellite of the Sun.

Automatic tracking system, which is installed at the rocket, in case of deviations from the calculated trajectory gives the signal, which affects the current intensity in each of 4 electro rocket engines, changing the traction force. After 6 days of movement the speed of rocket ER-7 reaches $25 \mathrm{~km} / \mathrm{s}$.

The rocket moves past the point 3 on the Earth orbit 2 (Figure 1). At this moment, the asteroid Apophis, while moving along its orbit 1 with speeds of 30 $\mathrm{km} / \mathrm{s}$, is in the point $3^{\prime}$. After 14 days of flight $(8.10 .28)$ the rocket reaches speeds of $70 \mathrm{~km} / \mathrm{s}$ and its weight has dropped from 28 to 25 tons.

The command to switch off electrorockets engines 3 is generated (Figure 2). During the further 10 days the rocket is moving at constant speed. After 24 days after the beginning of the flight (on 18 October) the rocket enters into braking mode. For this rocket commits manoeuvre, after which the thrust force vector of electrorocket engines changes its direction at $180^{\circ}$.

The braking mode lasts for 13 days. Rocket speed is reduced from $70 \mathrm{~km} / \mathrm{s}$ up to $30 \mathrm{~km} / \mathrm{s}$. Rocket weight becomes equal to $22 \mathrm{t}$.

While moving along the calculated trajectory 3 (Figure 1), rocket reaches the asteroid Apophis (in point 4' (Figure 1)), which is moving along the trajectory 3.

The final stage of capsule delivery on the surface of asteroid Apophis, begins. With the help of a manoeuvre the rocket makes the turn on $180^{\circ}$.

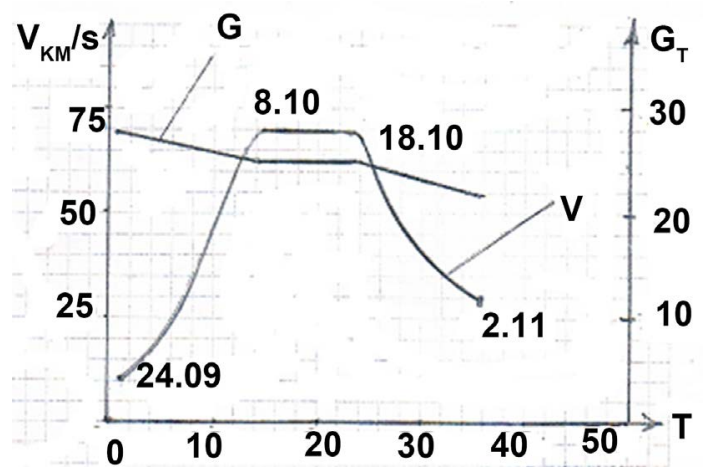

Figure 3. Process of changing the speed and mass of the rocket in time. 
Now the rocket ER-7 flies over the surface of the asteroid with speed of 30 $\mathrm{km} / \mathrm{s}$, i.e. with the speed of the asteroid. Parallel movement of two bodies at a distance of $10 \mathrm{~km}$ takes place.

The auto-tracking system, which by means of thrust control of electro rocket engines (Figure 2) provides synchronous movement of the rocket and asteroid, is switched on.

In so doing, the rocket carries out rapprochement with asteroid. When the height from the surface of the asteroid is $1500 \mathrm{~m}$ the command for descent the landing capsule 2 is given.

The locking device of docking unit 6 is actuated. The landing capsule is separated from the rocket 1 . The traction force of electric rocket engine 3 grows and rocket 1 moves away from the landing capsule 2. The landing capsule 2 under the influence of gravity starts to move to asteroid surface. And while doing so, it moves synchronously in parallel to the direction of asteroid movement. After 40 minutes the capsule is approaching to the asteroid surface with speed of $1.2 \mathrm{~m} / \mathrm{s}$.

At this moment chemical rocket engine 7 is switched on. The capsule loses weight and hovers above the asteroid surface at height of $400 \mathrm{~m}$. Under the influence of traction force of reactive chemical engines the capsule retains its position over the point of landing in the middle of the asteroid. By means of changing the traction force of chemical rocket engine 7 the capsule gently descends to the surface of the asteroid. For 10 seconds before touching the surface the chemical rocket engines are switched on, which are designed to press the capsule to the asteroid surface. After landing the pressing rocket engines continue to operate for $20 \mathrm{sec}$. At this moment, using the pyirocartridges, the system of harpoons, which are fixed on the surface of the asteroid, is switched on. Harpoons are installed on shoes of landing uprights of the capsule.

The landing capsule takes its stipulated in advance place on the surface of the asteroid.

After separation of the landing capsule the rocket ER-7 continues its movement along the calculated trajectory 4 (Figure 1 ) from point 4 - the separation place of the landing capsule to the point 6 , located on Earth orbit.

To save costly rocket ER-7 for further use, the time of the operation to eliminate the asteroid is postponed until the moment when the rocket ER-7 strays from the asteroid at the safe distance.

Calculations of the movement of the planet Earth, the asteroid Apophis and the rocket ER-7 have showed that the explosion of the charge, which was delivered by the landing capsule, should be carried out 1. 12.28 when asteroid Apophis will be in point 5', Earth at point 5, and rocket ER-7 at point 5". The distance between the Earth and the asteroid at the time of the explosion will be 64 million $\mathrm{km}$. The rocket ER-7 at the time of the explosion is located from the asteroid at distance of 22 million $\mathrm{km}$.

With the help of a telescope which is installed on the rocket the process of asteroid Apophis destruction is broadcasted to the Earth. 
The rocket ER-7 continues movement along the trajectory 4.

At 6.01.29 the command for braking is being generated. Electric rocket engines 3 are being switched on, the rocket is approaching Earth and 14.01.29 goes into its orbit.

Now let us return again to events, which occur on the surface of the asteroid Apophis starting with 2.11.28 in point 4 ' on the curve 1 (Figure 1 ).

It should be recalled that the asteroid moves from point $4^{\prime}$ towards point $5^{\prime}$ with a speed of $30 \mathrm{~km} / \mathrm{sec}$. At the same time, the Earth moves in its orbit 2 from point 4 towards the point 5 at a speed of $28 \mathrm{~km} / \mathrm{s}$.

After checking the readiness of the systems related to the nuclear charge, which are installed inside the landing capsule, the command is generated. The clock mechanism is switched on. 1.12.2028 the explosion of a nuclear charge is carried out.

One can consider that it will be a special day in history of mankind. In this day will become clear that there is a technology that allows eliminating any dangerous crazy asteroid. Inhabitants of planet Earth will observe in the sky atomic explosion at a distance of 64 million $\mathrm{km}$. They will see firework as a salute in honour of the salvation of human civilization.

\section{Design of the Electric Rocket}

The electric rocket ER-7 is shown in Figure 4.

Although in its basis the design principles of jet propulsion underlies, it is structurally different from traditional chemical rocket, which while moving undergoes the influence of gravity and the influence of atmospheric forces. This electric rocket designed to deliver payload while moving by means of electric rocket engines of type MARS in weightlessness and in conditions of deep space vacuum.

The detailed description of the design of the engine MARS is given in [3], and the main parameters and dimensions are shown in Table 2.

As working substance for the engine 4 (Figure 4) is used nitrogen, which in liquid state is kept in cylindrical cryostat 7. Cryostat 7 is made of carbon. It is placed along the axis of the rocket inside the aluminium hull 1 . In nasal part of the rocket the butt-end disc 5 is located and in its tail part -butt-end disk 6. In the butt-end disk 5 four electrorocket engines MARS are installed under angle $90^{\circ}$. In the butt-end disk 6 , along rocket axis the docking unit 8 is installed with which help the rocket connects with the payload. As the source of electrical power for the operation of electrical rocket engines the solar battery 2 is used.

The solar battery 2 is made of three-layer photovoltaic cells. The first layer of the photocell is gallium-indium phosphide. The second layer is gallium arsenide. The third layer is indium gallium arsenide. Three layers are separated by a dielectric, which provides for the tunnel effect. This design of a photovoltaic cell allows the use energy of sunlight across the full range of wavelengths (Table 3 ).

Rocket ER-7 case design is shown in Figure 5. 


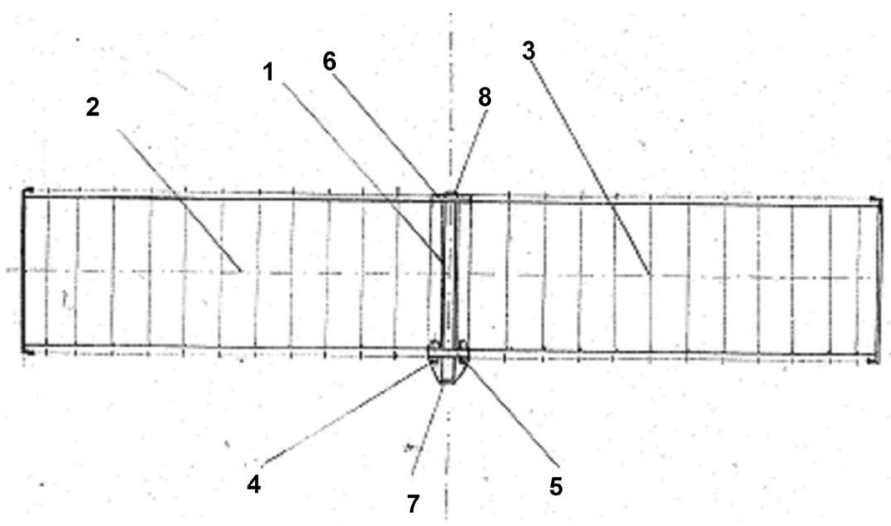

Figure 4. The electric rocket ER-7.

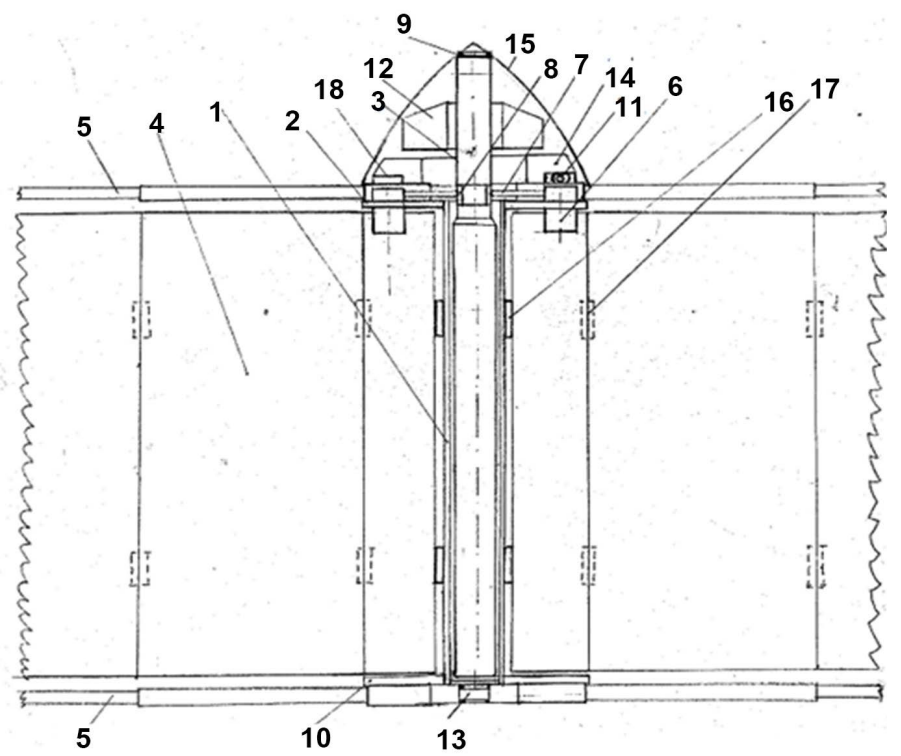

Figure 5. Rocket ER-7case design.

Table 2. Main parameters and dimensions of the engine MARS.

\begin{tabular}{cc}
\hline Traction force & $40 \mathrm{~N}$ \\
\hline Power & 400 kilowatt \\
Current & $400 \mathrm{~A}$ \\
Voltage & $1000 \mathrm{~V}$ \\
Efficiency & $94 \%$ \\
Specific impulse & $6000 \mathrm{~s}$ \\
Working substance consumption & $0,6 \mathrm{~g} / \mathrm{s}$ \\
Working substanced is charge velocity & $10 \mathrm{~km} / \mathrm{s}$ \\
Magnetic induction & $1.5 \mathrm{~T}$ \\
Anode diameter & $170 \mathrm{~mm}$ \\
Cathode diameter & $40 \mathrm{~mm}$ \\
Anode length & $80 \mathrm{~mm}$ \\
Cathode length & $60 \mathrm{~mm}$ \\
External cylinder diameter & $650 \mathrm{~mm}$ \\
External cylinder length & $450 \mathrm{~mm}$
\end{tabular}


Table 3. Solar battery characteristics.

\begin{tabular}{cc}
\hline Power & $1400 \mathrm{~kW}$ \\
\hline Voltage & $1000 \mathrm{~V}$ \\
Current & $1400 \mathrm{~A}$ \\
Efficiency & $40 \%$ \\
Wing length & $60 \mathrm{~m}$ \\
Wing width & $20 \mathrm{~m}$ \\
Mass & 4.8 tons \\
\hline
\end{tabular}

The mechanical basis of the design is aluminium casing 1 with nasal butt-end disk 2 and tail butt-end disk 10. Inside the casing, along rocket axis, the cryostat 3 is located, which is filled with liquid nitrogen. In case of refilling in the Earth orbit the feeding of liquid nitrogen is carried out using the on-board cryogenic pump 8.

The rocket docks with the refueller using the docking unit 9. Superconducting electric rocket engines 6 are installed in the nasal butt-enddisk 2. The engines are inserted into the holes in the butt-end disk which are located at angle $90^{\circ}$.

The solar battery panels 4 are connected with the hull by means of hinges 16 , and with each other the solar panels are connected by means of hinges 17.

The hinged system allows to assemble solar batteries inside the outer casing of the rocket during its launch into the Earth orbit.

Spreading of the solar panels is carried out with the help of the telescoping system 5 . The telescopic system 5 consists of inserted into each other cylindrical rods, which are fixed on both sides at the butt-end disks 2 and 10.

When feeding inside the telescopic system of gaseous nitrogen under pressure of 5 atmospheres, the system moves apart, taking together with itself the solar panels. To connect the rocket casing with the payload, which is the landing capsule (Figure 2), along the axis of the rocket the docking unit 13 is installed. Rocket nasal part is covered up by a cone 15 .

Inside of the nasal part the blocks of control system and of information transmission 12 are located. Block of power control system 14 is located on the butt end of disc 2

In the block 14 the power transistors, regulating current strength in electric motors 6 are installed.

In block 14 the system 18 for permanent tracking the Sun position and the low-thrust electrorocket engine 11, providing the rocket rotation around the longitudinal axis are also installed.

The calculation results of main dimensions and masses of the rocket ER-7 components are shown in Table 4.

\section{Landing Capsule with Nuclear Charge}

The landing capsule design is shown at Figure 6. 
Table 4. Main dimensions and masses of the rocket ER-7 components.

\begin{tabular}{cc}
\hline Casing length & $24 \mathrm{~m}$ \\
Casing diameter & $1.2 \mathrm{~m}$ \\
Butt-end disk diameter & $6 \mathrm{~m}$ \\
Mass: & \\
casing-2 $\mathrm{t}$ & \\
solar battery panel-4.8 t \\
$\begin{array}{c}\text { cryostat with liquid nitrogen-12 t } \\
\text { electrorocket engines-1.2 } \mathrm{t} \\
\text { payload-6 t } \\
\text { Total mass }\end{array}$ \\
\hline
\end{tabular}

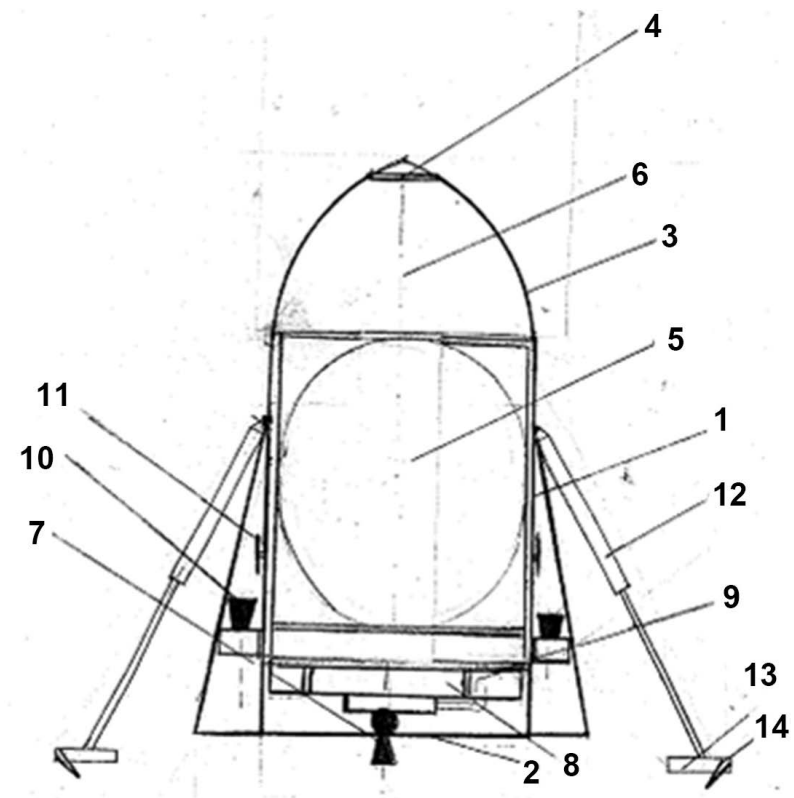

Figure 6. Landing capsule design.

The capsule has an outer casing 1 made of aluminium alloy. In the capsule bottom 2 chemical rocket engine 7 is located. As fuel for the operation of the engine 7 the hydrogen is used, which in liquid state is stored in a cryogenic tank 8 . The oxidizer (oxygen) for engine 7 operation is kept in the liquid state in a hollow cryogenic tank 9. The nasal part of the capsule 6 has outer cone 3 .

Under the cone 3 , a computer control system of nuclear charge explosion is located.

Here also the receiving-sending station is located for communication with command point, which is located on Earth. The nuclear charge designed to eliminate dangerous asteroid Apophis is located in the container 5.

In the manufacture of nuclear charge 5 the experience gained in many countries during 73 years since the establishment of the first two atomic bombs in the United States, is used.

The established power of the nuclear charge placed in the capsule is 6 megatons. 
For connection with electric rocket (Figure 4) capsule (Figure 6) has the docking unit 4. For manoeuvring of the capsule during landing on the asteroid's surface a system of low thrust engines 11 is installed. In order to provide the pressure of the capsule towards the asteroid's surface at moment of touching, the chemical oxygen-hydrogen rocket engines 10 are installed. The landing of the capsule on the asteroid's surface is done using shock-proof racks equipped with shoes 13.

Retention of the capsule after landing is done by means of harpoons 14, installed on the shoes 13 .

The dimensions of the landing capsule: Height-9.5 m

Diameter of the cylindrical part $-4.2 \mathrm{~m}$

Diameter of base $-6 \mathrm{~m}$.

Mass of the capsule-6.0 tons.

\section{Conclusions}

1) The comprehensive scientific research and technical design of the device intended for elimination of dangerous asteroid Apophis, which in April 2029 approaches Earth is carried out.

2) Two-stage method of nuclear charge delivery on the surface of the asteroid Apophis, using electric rocket is developed.

3) The design of electric rocket ER-7 in which installed electric rocket engines type MARS, getting power from solar batteries based gallium arsenide, is developed.

4) The successful elimination of asteroid Apophis, scheduled for January 2029, makes it possible to work out the technology owing to which disappears the constant threat of collision of the Earth with "crazy" asteroids.

\section{Conflicts of Interest}

The author declares no conflicts of interest regarding the publication of this paper.

\section{References}

[1] Е.Ю. Аристова и др. (2018) Лазерное моделирование разрушительного воздействияядерных взрывов на опасные астероиды. ЖЭТФ, 153, 157-172. (in Russian) https://doi.org/10.7868/S0044451018010145

[2] Roetsh Rosetta, T. Der Kometenjager. Space. Der Weltraum Magazin 1/2015 22-30.

[3] Rubinraut, A. (2018) The Space Cruise over the Route "Earth-Mars-Earth". Advances in Aerospace and Technology, 3, 20-47. https://doi.org/10.4236/aast.2018.32003

[4] Гуо П. Оценка точности определения параметров движения астероида Апофиз по измерениям комплекса “Небосвод”. Молодёжный НТ Вестник МГТУ им. Баумана. ФС 77-51038. (in Russian)

[5] Rubinraut, A. (2017) The Study of the Electrrocket Engine of the Future. Advances in Aerospace and Technology, 2. https://doi.org/10.4236/aast.2017.21001

[6] А. РойДвижениепоорбитам. Мир. Москва 1991. (in Russian) 